\title{
A randomized prospective study to compare the efficacy and safety of budesonide plus formoterol and tiotropium plus formoterol in patients having mild to moderate chronic obstructive pulmonary disease
}

\author{
Chandra Veer Singh', Aditya Kumar Gautam², Alok Dixit ${ }^{1}$, \\ Amit Vikram Singh ${ }^{1 *}$, Sandeep Kumar Singh ${ }^{3}$
}

\begin{abstract}
${ }^{1}$ Department of Pharmacology and Therapeutics, ${ }^{2}$ Department of Respiratory Medicine, Uttar Pradesh University of Medical Sciences, Saifai, Etawah, Uttar Pradesh, India

${ }^{3}$ Gen Tox Research and Development, Lucknow, Uttar Pradesh, India
\end{abstract}

Received: 15 January 2021

Revised: 01 February 2021

Accepted: 02 February 2021

\section{*Correspondence:}

Dr. Amit Vikram Singh,

Email: dramitvsingh@gmail.com

Copyright: (C) the author(s), publisher and licensee Medip Academy. This is an open-access article distributed under the terms of the Creative Commons Attribution Non-Commercial License, which permits unrestricted non-commercial use, distribution, and reproduction in any medium, provided the original work is properly cited.

\begin{abstract}
Background: Chronic obstructive pulmonary disease (COPD) is a leading respiratory illness affecting the quality of lives around the world. The present study aims to compare the efficacy and safety of combination of inhaled corticosteroid (ICS) and long acting $\beta 2$ agonist (LABA) with long acting $\beta 2$ agonist and long acting muscarinic antagonist (LAMA) in treatment of mild to moderate COPD in a tertiary care hospital.

Methods: Total 132 patients with COPD were recruited on the basis of inclusion and exclusion criteria for 8 weeks study from outpatient clinic. A complete pulmonary examination including spirometry examination was done to rule out severe and very severe forms of COPD. Spirometry was performed at the time of recruitment for evaluation of forced expiratory volume in one second (FEV1) and measurement of $\mathrm{SpO}_{2}$ at the time of recruitment at 2 weeks and 8 weeks. Appropriate statistical methods were used to compare the qualitative and quantitative primary and secondary efficacy end points, $\mathrm{p}$ value $<0.05$ was considered significant.

Results: On analysis, there was a significant difference $(\mathrm{p}<0.05)$ was observed in $\mathrm{FEV} 1$ and $\mathrm{SpO}_{2}$ from baseline in ICS plus LABA group $(n=66)$. A similarly significant difference $(\mathrm{p}<0.05)$ was observed in LABA and LAMA group ( $\mathrm{n}=66$ ). On comparison between ICS plus LABA and LABA plus LAMA no significant difference in FEV1 and SpO2 was observed between the two groups. More adverse drug reactions were observed in ICS plus LABA group than LAMA plus LABA group.

Conclusions: Combination of ICS and LABA combination is as effective as combination of LABA and LAMA in patients having mild to moderate COPD. However, LABA and LAMA combination is preferable because it is associated with fewer side effects.
\end{abstract}

Keywords: COPD, Spirometry, FEV1, Oxygen saturation

\section{INTRODUCTION}

Chronic obstructive pulmonary disease (COPD) is a common disorder of the airway affecting the quality of lives around the world. The World health organization defines COPD as chronic obstruction of airflow that interferes with normal breathing and is not fully reversible. In 2016 there were 251 million cases of COPD globally and it is estimated that COPD causes 3.15 million deaths per year. ${ }^{1}$ The healthcare burden of COPD can be as high as 50 billion dollars in USA where COPD is the third leading cause of mortality. In India three out of five leading causes of mortality include non-communicable 
diseases where COPD is the second biggest cause of mortality. The prevalence ranged between 2 to $22 \%$ among men and 1.2 to $19 \%$ among women. ${ }^{2}$ In India Disability adjusted life years (DALYs) due to COPD increased by $36.3 \%$ and it has become the second leading cause. The prevalence of COPD has increased by $29.2 \%$ which is a serious public health concern. ${ }^{3}$ Cigarette smoking is the most significant cause of COPD. Around $15 \%$ of smokers develop progressively disabling symptoms in their 4th and 5 th decade of life. ${ }^{4}$ Nearly $80 \%$ of COPD patients have significant exposure to tobacco smoke, and remaining $20 \%$ have evidence of exposure to environmental smoke, occupational dusts and chemicals, and indoor air pollution from biomass fuel. Airway infection, allergy and hereditary factors (e.g., deficiency of $\alpha-1$ antitrypsin) have been implicated in chronic bronchitis.4 COPD patients characteristically present with complaints of excessive cough, shortness of breath and sputum production in 5th or 6 th decade of life. The late stage of COPD is characterized by presence of pulmonary hypertension, cor pulmonale, pneumonia and chronic respiratory failure. A hallmark of COPD is the periodic exacerbation. These exacerbations are precipitated by infection or environmental factors. ${ }^{5}$ In pulmonary function testing, a post bronchodilator FEV1/ FVC ratio of $<0.70$ is considered diagnostic for COPD. The Global Initiative for chronic obstructive lung disease (GOLD) categorizes airflow limitation into four stages. ${ }^{6}$ GOLD-1 (MILD): FEV1 $\geq 80 \%$ predicted, GOLD-2 (MODERATE): $50 \% \leq$ FEV $1<80 \%$ predicted, GOLD-3 (SEVERE): $30 \% \leq$ FEV $1<50 \%$ predicted and GOLD-4 (VERY SEVERE): FEV1<30\% predicted.

Combinations of ICS and LABA have been the mainstay of treatment for COPD for decades but the major drawback is the number of serious steroid related side effects. Whereas LAMA and LABA combination is well tolerated with virtually no steroid related side effects. There are very few studies comparing the efficacy and safety of combination of inhaled budesonide plus formoterol and combination of inhaled tiotropium plus formoterol in Indian population to the best of our knowledge. The main purpose to carry out this study is to compare the efficacy and safety of combination of budesonide $400 \mathrm{mcg}$ plus formoterol $12 \mathrm{mcg}$ with tiotropium $18 \mathrm{mcg}$ plus formoterol $12 \mathrm{mcg}$ in the treatment of COPD in Indian population.

\section{METHODS}

The present study was conducted on patients with mild to moderate illness attending the outpatient department of Respiratory Medicine in UPUMS, Saifai, Etawah from March 2019 to March 2020 Total 132 patients were recruited over the time based on inclusion and exclusion criteria and followed up for eight weeks.

\section{Inclusion criteria}

Inclusion criteria were 1) age $>40$ years of either sex with clinical diagnosis of COPD (excessive cough, sputum production and shortness of breath) or receiving standard treatment, 2) chronic smokers or those who had significant exposures to tobacco smoke, occupational dusts and chemicals, and indoor air pollution from biomass fuel, 3 ) newly diagnosed patients (not taking any medication for COPD).

\section{Exclusion criteria}

Exclusion criteria were 1) severe and very severe (Gold 3 and Gold 4) form of COPD 2) any concurrent lung infection, asthma or bronchiectasis 3) patients with known history of hypersensitivity to any component under study 4) pregnant or nursing women 5) unstable or uncontrolled cardiovascular disease.

The patients were recruited after obtaining clearance from the institutional ethics committee (Ethical clearance number 156/2018) and written informed consent was taken from the patients after explaining the nature and possible consequences of their participation in the study. All participants had the right to pull out from the study at any time during the course of study without prior intimation to investigators with no consequence on their treatment.

The patients were divided into 2 groups; group I: patients receiving budesonide $400 \mathrm{mcg}$ plus formoterol $6 \mathrm{mcg}$ combination, inhaler or rotahaler with rotacapsule, 2 puff twice daily. Group II: Patients receiving Tiotropium $18 \mathrm{mcg}$ plus formoterol $12 \mathrm{mcg}$ combination, inhaler or rotahaler with rotacapsule, 2 puff once daily.

Group I patients received two puffs of inhaler which is a combination of budesonide $400 \mathrm{mcg}$ plus formoterol 6 mcg twice daily, while group II patients received tiotropium $18 \mathrm{mcg}$ plus formoterol $12 \mathrm{mcg}$ once daily. Pulse rate, blood pressure, spirometry, pulse oximetry, adverse drug reactions and exacerbation rate, were assessed thoroughly at subsequent follow up visits at 2 weeks and 8 weeks. All the patients were assessed on intention to treat principle. Appropriate statistical method was used to compare the qualitative, quantitative primary and secondary efficacy end points, $p$ value $<0.05$ was considered significant.

In the current study, we first compared three groups, based on timeline (baseline vs 2 weeks vs 8 weeks) of each treatment. All assumptions for ANOVA were checked before final analysis. Means and standard deviations were calculated for all tests performed. In case of nonparametric approach, median values were calculated.

As there were different times of measurements, we performed repeated measure of ANOVA to compare the mean. Posthoc analysis was performed to identify statistically significant groups. Multiple paired t-test was used to perform posthoc analysis. $\mathrm{P}$ values obtained after paired t-test was adjusted by Bonferroni correction to avoid any multiple comparison issue. To compare the difference between treatments (ICS+LABA vs 
LAMA+LABA), mixed model ANOVA was used. Data analysis was performed using SPSS 24.

\section{RESULTS}

Out of 150 recruited patients, 11 patients could not perform spirometry test, 4 patients did not turn up for further follow up and 3 patients discontinued drugs. Only 132 patients who met the inclusion criteria were observed within the study period. All patients were randomised into 1:1 ratio and were divided into two treatment groups. Group I comprised of 66 patients and were treated with budesonide $400 \mathrm{mcg}$ plus formoterol $6 \mathrm{mcg}$ combination, inhaler or rotahaler with rotacapsule, 2 puffs twice daily while group II consisted of 66 patients and were treated with tiotropium $18 \mathrm{mcg}$ plus formoterol $12 \mathrm{mcg}$ combination, inhaler or rotahaler with rotacapsule, 2 puffs once daily. All demographic and baseline characteristics are shown in Table 1 .

Table 1: Baseline data on demographic parameter in budesonide plus formoterol combination and tiotropium plus formoterol combination treatment group of COPD patients respectively.

\begin{tabular}{|c|c|c|}
\hline Variables & $\begin{array}{l}\text { Group I } \\
\text { (Budesonide } 400 \text { mcg plus } \\
\text { Formoterol } 6 \text { mcg) }\end{array}$ & $\begin{array}{l}\text { Group II } \\
\text { (Tiotropium } 18 \mathrm{mcg} \text { plus } \\
\text { Formoterol } 12 \mathrm{mcg} \text { ) }\end{array}$ \\
\hline Total numbers & 66 & 66 \\
\hline Age $($ mean \pm SD $)$ years & $49.98 \pm 5.34$ & $47.42 \pm 4.46$ \\
\hline Male & $59(89.4 \%)$ & $59(89.4)$ \\
\hline Female & $7(10.6 \%)$ & $7(10.6 \%)$ \\
\hline Male/female ratio & $59 / 7$ & $59 / 7$ \\
\hline Heart rate $($ mean \pm SD) & $80.56 \pm 5.902$ & $78.59 \pm 6.702$ \\
\hline Systolic blood pressure $(\mathrm{mm}$ of $\mathrm{Hg})($ mean $\pm \mathrm{SD})$ & $128.33 \pm 10.98$ & $124.58 \pm 11.93$ \\
\hline Diastolic blood pressure (mm of $\mathrm{Hg})($ mean \pm SD) & $74.94 \pm 8.638$ & $73.12 \pm 8.464$ \\
\hline $\mathrm{SpO}_{2}$ (oxygen saturation) $($ mean $\pm \mathrm{SD})$ & $95.439 \% \pm 1.337 \%$ & $95.272 \% \pm 1.234 \%$ \\
\hline $\mathrm{FEV}_{1}(\operatorname{mean} \pm \mathrm{SD})$ & $64.44 \pm 4.548$ & $65.39 \pm 3.953$ \\
\hline
\end{tabular}

\section{FEV1 (forced expiratory volume in the first second)}

In group I there is an increase in mean from baseline to 2 weeks and then 2 weeks to 8 weeks. Homogeneity-ofvariance-of-differences (or sphericity) met and results were Hence, suggests that there is statistically significant difference among some means. When results were compared pairwise, all three groups showed statistically significant difference $(\mathrm{p}<0.0001)$, even after adjusting for Bonferroni correction. Budesonide/ formoterol significantly reduced all symptoms within the first week of treatment. The improvements in FEV1 were sustained with budesonide/ formoterol throughout the study period.

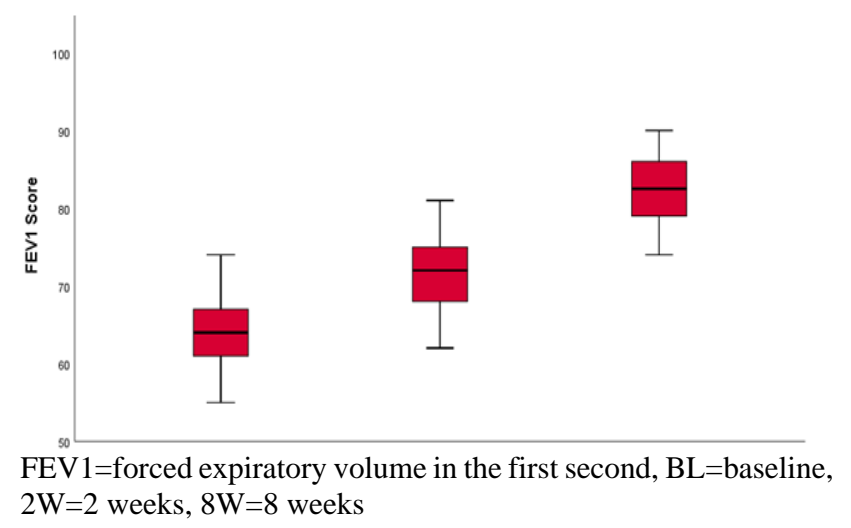

Figure 1: Boxplot presenting the difference in FEV1 among baseline (no treatment), 2 weeks and 8 weeks for group $I$.
In group II there is an increase in mean from baseline to 2 weeks and then 2 weeks to 8 weeks. $\mathrm{P}$ value for homogeneity-of-variance-of-differences (or sphericity) is statistically significant $(\mathrm{p}<0.0001)$. When results were compared pairwise, all three groups showed statistically significant difference $(\mathrm{p}<0.0001)$. The improvements in FEV1 were sustained with tiotropium/formoterol throughout the study period.

At the baseline, 2 weeks and 8 weeks the obtained mean value of group1 and group2 is near about similar. Mauchly's test for sphericity did not meet $(\mathrm{p}=0.001)$. Hence, results were adjusted for degrees of freedom to obtained repeated measures $p$ value. There is no statistically significant $(\mathrm{p}=0.468)$ difference between both treatment groups. It can be seen in figure 9 that effect of time variable did not depend on the groups. Looking at the two lines, we see that group1 has slightly higher mean at baseline. Estimated marginal means are nearly overlapping with each other. It also suggests there is no statistical interaction (time* ${ }^{*}$ group) and it was also confirmed by mixed ANOVA model $(\mathrm{p}=0.306)$.

The mean value of $\mathrm{SpO} 2$ (oxygen saturation) in group I at baseline was (mean \pm SD) $95.44 \% \pm 1.34 \%$, at 2 weeks $($ mean \pm SD) $97.14 \% \pm 1.24 \%$ and at 8 weeks (mean \pm SD) $97.17 \% \pm 1.22 \%$. There was a change in mean from baseline to 2 weeks. However, means are nearly equal at 2 week and 8 weeks. Results also showed significant difference $(\mathrm{p}<0.05)$ among mean values. When results were compared pairwise, baseline and week 2 , and baseline and week 8 
yielded statistically significant difference $(p<0.0001)$. No statistical difference identified between week 2 and week 8 ( $>0.05)$.

The mean value of $\mathrm{SpO} 2$ (oxygen saturation) in group II at baseline was (mean \pm SD) $95.27 \pm 1.23 \%$, at 2 weeks $($ mean \pm SD) $96.85 \% \pm 1.03 \%$ and at 8 weeks (mean \pm SD)
$97.06 \pm 0.91 \%$. There is not much change in mean at any given treatment time. Our results yielded statistically significant difference $(\mathrm{p}<0.0001)$ among some means. Pairwise test confirmed the statistical difference $(\mathrm{p}<0.05)$ between baseline and week 2 and baseline and week 8 . There was no significant difference at week 2 and week 8 .

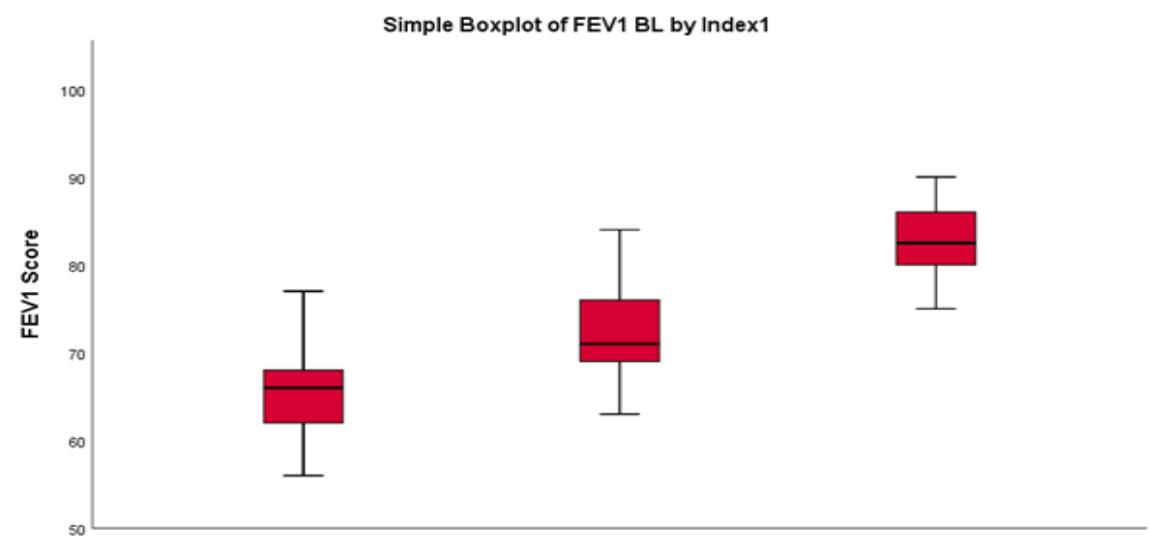

Figure 2: Boxplot presenting the difference in FEV1 among baseline (no treatment), 2 weeks and 8 for group II.

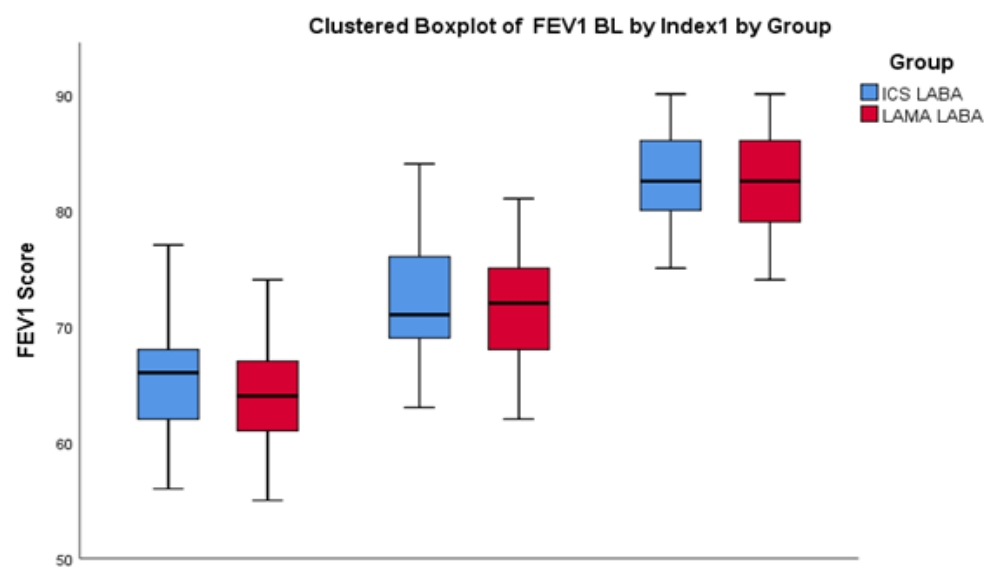

Figure 3: Box plot comparing the difference among baseline (no treatment) vs week 2 vs week 8 of both treatments.

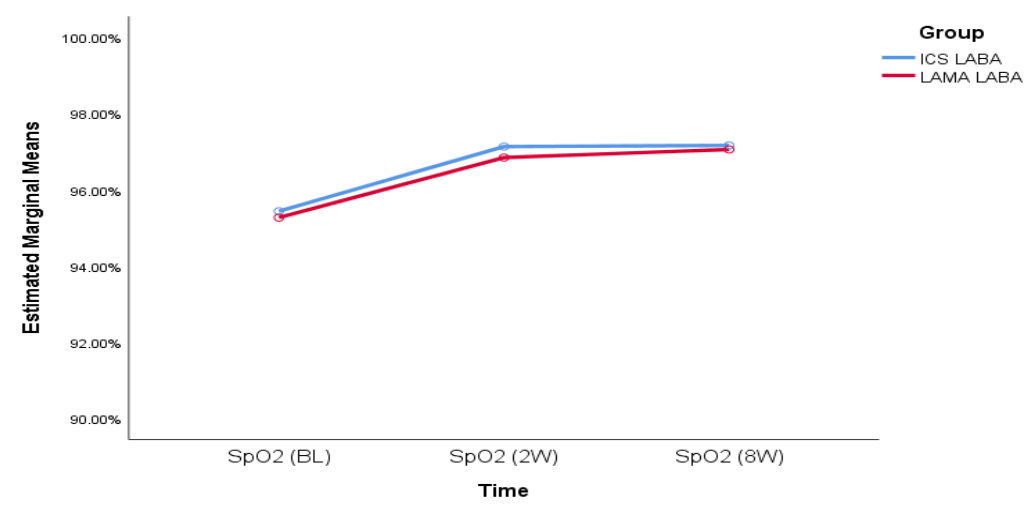

Figure 4: Estimated marginal means of SpO2 in group I and group II.

Group I had slightly higher mean in comparison to group II at baseline but at 8 th week both groups showed nearly similar mean. When we compared both treatment, result did not show any statistically significant difference 
$(p=0.236)$. It can be seen in figure 4 that effect of time variable did not depend on the groups. Looking at the two lines, we see that ICS + LABA group has slightly higher mean. Estimated marginal means are nearly parallel to each other. It also suggests there is no statistical interaction (time * group) and also confirmed by mixed ANOVA model.

\section{Adverse drug reactions}

In group I, following adverse drug reactions were observed; sore throat, hoarseness of voice, oral ulcers, tremors, 2 patients showed acute exacerbation and 1 had pneumonitis. In group II, following adverse drug reactions were observed; dryness of mouth, palpitations, tremors and 2 patients developed urinary retention. After that we have done Fisher's exact test and we observed that there is statistically significant difference $(p<0.001)$ between group I and group II.

\section{DISCUSSION}

This study shows that treatment with budesonide/formoterol and tiotropium/ formoterol results in significant improvement in patients having mild to moderate chronic obstructive pulmonary disease. Current medical therapy for COPD provides only symptomatic relief and improvement in quality of life with little or no effect on disease progression. ${ }^{7}$ Bronchodilators are the mainstay of therapy in COPD. Current GOLD guideline recommends regular treatment with long-acting bronchodilators since they are more effective and convenient than treatment with short-acting bronchodilator. ${ }^{8}$

In patients with moderate to severe COPD and exacerbation, an ICS/LABA combination is more effective than ICS or LABA alone in improving lung function and health status of the patients. ${ }^{9}$ In our study budesonide/formoterol combination was as effective as tiotropium/formoterol combination. Celli et al compared the efficacy of budesonide/formoterol combination with formoterol alone for FEV1, forced vital capacity and inspiratory capacity and found improvement in spirometric indices. ${ }^{10}$ In contrast, present study included relatively more relevant parameters in comparing the clinical efficacy of budesonide/formoterol combination versus tiotropium/formoterol combination for mild to moderate COPD. We assessed the efficacy outcomes by using different spirometric indices, capable of indicating the effectiveness of budesonide/ formoterol when compared to tiotropium/ formoterol. Budesonide/ formoterol is taken twice daily with a pressurized metered-dose inhaler, and it is considered to be convenient and therefore became the preferred choice for most of the patients. ${ }^{11}$ In addition it is not only economical but also more effective therapy for patients with moderate to severe COPD. ${ }^{12}$ The results of the Tashkin study suggest a numerically greater improvement in ex-smokers compared with current smokers in the formoterol/ tiotropium group; with improvements in FEV1 ranging from $34.4 \%$ to $38.4 \%$ respectively and the present study shows the improvement in FEV1 ranging from $65.39 \%$ to $71.92 \%$ respectively. ${ }^{13}$

Johnson in his study showed that tiotropium and salmeterol reduce airflow resistance and hyperinflation but may also directly or indirectly have an effect on various aspects of lung inflammation. ${ }^{14}$ In our study tiotropium/formoterol also reduced airflow resistance and improved FEV1. Cazzola et al suggested that tiotropium ensures prolonged bronchodilation, whereas formoterol adds fast onset and a greater peak effect, the two drugs appear complementary to each other. Both the drugs improved spirometry indices and quality of life as well. ${ }^{15}$ Our study also suggests that tiotropium/ formoterol improves FEV1 and also improves quality of life. LAMAs and LABAs may have the potential to increase heart rate and other cardiac events. Hence, there is a concern about a possible increase in adverse events with LAMA/LABA combination therapy. ${ }^{16}$ In the present study LAMA/LABA increased the heart rate but very few patients complained about palpitation. Apart from LAMA/LABA the ICS/LABA also increased the heart rate. Wedzicha et al showed that combined bronchodilator therapy with a LABA and a LAMA had greater efficacy in the reduction of exacerbation rates than did LAMA monotherapy. ${ }^{17}$ The present study suggests that LABA/LAMA has better efficacy in reducing exacerbation than ICS/ LABA. It also suggested that inhaled glucocorticoids may not be essential for the prevention of COPD exacerbations in patients receiving therapy with a LABA and a LAMA. The study of Aaron et al suggested that salmeterol with tiotropium shows no significant reduction in the proportion of patients with exacerbations versus tiotropium monotherapy.

The results of our study raise the possibility that combination bronchodilator therapy may provide beneficial effects in patients with more advanced stages of disease.18In current study tiotropium with formoterol combination reduces the occurrences of exacerbations and improves the quality of life as well. The evidence is strong that dual bronchodilation is always more effective than a LAMA or LABA alone in improving lung function and controlling symptoms, and also in reducing the risk of exacerbations. It gives a solid reason to start the treatment of COPD with dual bronchodilation.19In this study the treatment with a LABA/LAMA combination appears to be equally effective as a LABA/ICS combination in preventing COPD exacerbations. However, the LABA/LAMA combination tends to be associated with fewer hospitalizations for pneumonia. ${ }^{20}$ The present study also shows that formoterol/budesonide combination is as effective as tiotropium/formoterol combination but the latter combination appears better because it produced fewer adverse drug reactions.

\section{Limitations}

The patients could be followed for only 8 weeks because of declaration of COVID pandemic. A longer follow up of 
about 6 months could have provided concrete evidence of efficacy and safety.

\section{CONCLUSION}

The present study was conducted to compare the efficacy and safety of budesonide plus formoterol and tiotropium plus formoterol in patients having mild to moderate COPD. Budesonide/ formoterol combination is as effective as tiotropium/ formoterol combination, but tiotropium/ formoterol is a better tolerated combination because of lesser adverse drug reactions.

\section{Funding: No funding sources}

Conflict of interest: None declared

Ethical approval: The study was approved by the Institutional Ethics Committee

\section{REFERENCES}

1. Chronic obstructive pulmonary disease (COPD). World Health Organization. Available at: http://www.who.int/news-room/factsheets/detail/chronic-obstructive-pulmonary-disease(copd). Accessed on 25 November 2020

2. Jindal SK, Aggarwal AN, Gupta D. A review of population studies from India to estimate national burden of chronic obstructive pulmonary disease and its association with smoking. India J Chest Dis Allied Sci. 2001;43:139-47

3. ICMR-PHFI-IHME. India: Health of the Nation's States; 2017

4. MacNee W. Pathology, pathogenesis, and pathophysiology. Bio Med J. 2006;332(7551):1202-4.

5. Chesnutt AN, Chesnutt MS, Prendergast TJ, Chronic Obstructive pulmonary disease. In: Maxine A. Papadakis, Stephen J. Mcphee, Associate editor Michel W. Rabow, Pulmonary disorders, 57th edition California; Mc Graw Hill Education. 2018; 263.

6. New GOLD global strategy for diagnosis, management and prevention of COPD. European Respiratory Society. Available from: https://www.ersnet.org/the-society/news/new-goldglobal-strategy. Accessed on 20 November 2020.

7. Montuschi P. Pharmacological treatment of chronic obstructive pulmonary disease. Int J Chron Obstruct Pulm Sisease. 2006;1(4):409.

8. Rabe KF. Global strategy for the diagnosis, management, and prevention of chronic obstructive pulmonary disease: GOLD executive summary. Am. J. Respire. 2007;176(6):532-55.

9. Nannini LJ, Lasserson TJ, Poole P. Combined corticosteroid and long acting beta (2) agonist in one inhaler versus long acting beta (2) agonist for chronic obstructive pulmonary disease. Cochrane Database Syst Rev. 2012;9(9):CD006829.

10. Celli BR, Tashkin DP, Rennard SI. Bronchodilator responsiveness and onset of effect with budesonide/formoterol pMDI in COPD. Respir Med. 2011;105:1176-88

11. Ferguson GT, Tashkin DP, Skärby T. Effect of budesonide/formoterol pressurized metered-dose inhaler on exacerbations versus formoterol in chronic obstructive pulmonary disease: The 6-month, randomized RISE (Revealing the Impact of Symbicort in reducing Exacerbations in COPD) study. Respir Med. 2017;132:31-41.

12. Lofdahl CG, Ericsson A, Svensson K, Andreasson E. Cost effectiveness of budesonide/formoterol in a single inhaler for COPD compared with each monocomponent used alone. Pharmacoeconomics. 2005;23:365-75.

13. Tashkin DP, Varghese ST. Combined treatment with formoterol and tiotropium is more efficacious than treatment with tiotropium alone in patients with chronic obstructive pulmonary disease, regardless of smoking status, inhaled corticosteroid use, baseline severity, or gender. Pulm Pharmacol Ther. 2011;24(1):147-52.

14. Johnson M. Beta-2 agonists. Chron Obstruct Pulm Disease. 2007:669-84.

15. Cazzola M. The pharmacodynamic effects of single inhaled doses of formoterol, tiotropium and their combination in patients with COPD. Pulm Pharmacol Ther. 2004;17(1):35-9.

16. Rogliani P, Matera MG, Ora J. The impact of dual bronchodilation on cardiovascular serious adverse events and mortality in COPD: a quantitative synthesis. Int $\mathbf{J}$ Chron Obstruct Pulmon Dis. 2017;12:3469-85.

17. Wedzicha JA, Decramer M, Ficker JH, Niewoehner DE, Sandström T, Taylor AF, et al. Analysis of chronic obstructive pulmonary disease exacerbations with the dual bronchodilator QVA149 compared with glycopyrronium and tiotropium (SPARK): a randomised, double-blind, parallel-group study. Lancet Respirat Medic. 2013;1(3):199-209.

18. Aaron SD, Fergusson D, Marks GB, Suissa S, Vandemheen KL, Doucette S, et al. Counting, analysing and reporting exacerbations of COPD in randomised controlled trials. Thorax. 2008;63(2):122-8.

19. Kruis AL, Ställberg B, Jones RC. Primary care COPD patients compared with large pharmaceuticallysponsored COPD studies: an UNLOCK validation study. PLoS One. 2014;9(3):e90145.

20. Suissa S, Dell'Aniello S, Ernst P. Comparative effectiveness and safety of LABA-LAMA vs LABAICS treatment of COPD in real-world clinical practice. Chest. 2019;155(6):1158-65.

Cite this article as: Singh CV, Gautam AK, Dixit A, Singh AV, Singh SK. A randomized prospective study to compare the efficacy and safety of budesonide plus formoterol and tiotropium plus formoterol in patients having mild to moderate chronic obstructive pulmonary disease. Int J Basic Clin Pharmacol 2021;10:245-50. 